\title{
El cine en la realidad de las aulas
}

\author{
José Rodríguez Terceño \\ Universidad Complutense de Madrid \\ josechavalet@gmail.com
}

\begin{abstract}
Resumen:
La sociedad contemporánea inmersa en las nuevas tecnologías de la información y comunicación necesita de una educación multimedia apropiada no sólo para el correcto uso de estas herramientas sino también para poder aprovechar al máximo su potencial educativo. Comenzando por una necesaria formación de los docentes y transmitiendo los conocimientos a los discentes. La implementación de las nuevas tecnologías está siendo lenta y en algunos casos es un mero acompañamiento, como le ha ocurrido al cine desde sus orígenes, pese al esfuerzo de muchos por cambiar esta realidad. Recientes investigaciones y proyectos científicos nos han descubierto las posibilidades que ofrecen las aplicaciones de las TT.II.CC.. El cine debe tomar ejemplo y aumentar su presencia en las aulas españolas hasta ocupar el lugar que se merece dentro del panorama educativo nacional.
\end{abstract}

Palabras clave: cine; historia; docencia; proyectos.

\section{Cinema in the classroom reality}

\begin{abstract}
:
Contemporary society immersed in the new technologies of information and communication needs a proper media education not only for the proper use of these tools but also to be able to maximize their educational potential. Starting with the necessary teacher training and transmitting knowledge to learners. The implementation of new technologies is slow and in some cases is a mere accompaniment, as has happened to film since its inception, despite the efforts of many to change this reality. Recent research and scientific projects we have discovered the potential applications of TT.II.CC.. The film should take example and increase its presence in the classroom Spanish to occupy the place it deserves in the national educational landscape.
\end{abstract}

Key words: film; history; teaching; projects.

\section{Referencia normalizada:}

Rodríguez Terceño, J. (2014): El cine en la realidad de las aulas. Historia y Comunicación Social. Vol. 19. Núm. Especial Marzo. Págs. 565-574.

Sumario: 1. Introducción. 2. Oposición historiográfica. 3. El cine entra en las aulas. 4. Conclusiones. 5. Bibliografía.

\section{Introducción}

La implementación de las Tecnologías de la Información y la Comunicación en las aulas españolas está dejando de ser, cada vez más, un proyecto, una hipótesis, 
una teoría, una propuesta de futuro que defendían la gran mayoría de docentes para convertirse en una realidad. Una realidad práctica y tangible, más que teórica, gracias al esfuerzo y la voluntariedad de los profesionales de la docencia en introducir las nuevas herramientas informativas y comunicativas entre un alumnado al que se ha nominado como 'nativo digital'. Frente a estos nativos digitales muchos jóvenes docentes, y otros no tan jóvenes pero si ilusionados (aquellos que se denominan 'dinosaurios analógicos', que se distinguen de sus compañeros 'analógicos' más reaccionarios y ya extintos en su motivación a la hora de utilizar estos nuevos instrumentos aplicados a la enseñanza) defienden la idea, la necesidad por mejor decir, de introducir estas modernas aplicaciones en sus clases, pues ellas dominan la vida social y cultural de nuestros jóvenes (aunque este aspecto habría que definirlo con mayor precisión, pues las inquietudes culturales, y por ende, educativas -hambre de conocimientos- de las nuevas generaciones quizás brille por su ausencia) y, de esta forma, generar motivación entre los alumnos (con toda seguridad, y a sabiendas de que la generalización está siempre penalizada, el mayor problema social entre los jóvenes, la falta absoluta de motivación); acercarles las herramientas necesarias para alcanzar el conocimiento de una forma que ellos no consideren aburrida, carente de emoción ${ }^{1}$ o de premio (nuestros jóvenes, educados en una sociedad esencialmente consumista, no llevan a cabo ninguna acción si no obtienen algo a cambio, entiéndase recompensas ${ }^{2}$ o convalidación de créditos por ejemplo).

Entre esas nuevas tecnologías se encuentra el cine, siempre presente en las aulas españolas desde la popularización que adquirió el vídeo doméstico, aunque su presencia no estaba -ni está- aparejada a la importancia que se merece, pues, como es de sobra sabido, y no revelamos nada nuevo, el cine es hoy por hoy uno de los agentes moldeadores de las mentalidades más representativo, "un poderoso reflejo de unas determinadas maneras de vivir y de pensar" (Breu, 2012: 7). A pesar de ello, su importancia en los programas educativos se limita a actuar como complemento audiovisual para una explicación del profesor o para intervenir como el mejor de los sustitutos cuando los docentes no pueden impartir su asignatura y necesitan algo con lo que entretener al alumnado.

No obstante, y como ya hemos señalado, son muchos los profesionales de la docencia que tienen un interés real en introducir el cine como herramienta educativa. Nuestro objetivo en el presente artículo es establecer las principales oposiciones a las que se enfrenta el cine en las aulas, esgrimidas en su mayoría desde la atalaya de la 'verdadera' historiografía, así como enumerar los principales proyectos oficiales y no oficiales que algunos docentes, investigadores e historiadores han desarrollado para que el cine ocupe su lugar dentro de la enseñanza de nuestro país y se convierta, como muchos imaginaban esperanzados en los albores del siglo XIX, en la mejor escuela para los niños (Griffith, Edison, Marinetti, entre muchos otros), pues, no conviene olvidar, el cine es "un punto de intersección de una serie de lenguajes fundamentales para el desarrollo del intelecto humano" (Ambròs y Breu, 2007: 9). 


\section{Oposición historiográfica}

El distanciamiento que existe entre el cine y la historia, y su aplicación práctica en la docencia, es, aún hoy, enorme. Pese a la consolidación de las nuevas tecnologías de la comunicación entre los jóvenes, donde la palabra escrita ha evolucionado (quizás peligrosamente) hasta convertirse en un complemento del lenguaje audiovisual -es preciso anotar la enseñanza de la comunicación audiovisual (narrativa) que ofrecen estas tecnologías como una asignatura pendiente más de la educación española tanto a nivel escolar como universitario-, su aplicación práctica en las aulas patrias brilla por su ausencia. Dentro de este grupo, el cine ocupa uno de los peldaños más bajos, postergado a completar visualmente las fuentes escritas (de las que, extrañamente, no se duda de su autenticidad, manipulación o intencionalidad) o, en el peor de los casos, ocupar el tiempo de una clase sin profesor para no perder horas lectivas.

Para algunos historiadores, el cine es una opción más que aceptable de mejorar una disciplina por otro lado difícil de acercar a los alumnos ( $\mathrm{y}$ al público en general). Pero para otros no es más que "un fantasma que amenaza los dominios de la ciencia histórica, haciendo que el gran público se conforme con historietas más o menos espectaculares, en vez de con la Historia con mayúsculas" (De Pablo, 2001: 9).

Las causas de este distanciamiento están muy claras para algunos autores interesados (una mayoría) en la aplicación del cine en el ámbito docente. Ramón Alquézar señala tres causas principales: la formación universitaria con la que se ha instruido a los historiadores y que no contempla la utilización científico-didáctica de los medios audiovisuales (un completo anacronismo en los tiempos que corren); los métodos habituales de análisis histórico basados en cadencias más lentas y autorregulables de los documentos escritos que dificultan la aplicación de un filme por sus características técnicas; y la carencia de teorías y métodos para una epistemología de la historia que provocan el temor a caer en el empirismo. Ángel Luis Hueso, por su parte, apunta dos razones más, la apreciación del cine por parte de la mayoría de los historiadores como un simple pasatiempo o espectáculo popular y la desconfianza que generar los especialistas en historia del $\operatorname{cine}^{3}$, a quienes no consideran auténticos historiadores, pues no proceden, según los autoproclamados verdaderos historiógrafos, de su ámbito académico sino que pertenecen al mundo cinematográfico (técnicos, críticos, comunicólogos sociales, etcétera). Para Julio Montero, la razón de este distanciamiento se encuentra en la percepción del cine que tienen los historiadores, pues muchos de ellos creen firmemente que las películas falsifican la historia -no como una intención manipuladora intencionada, que también, sino como una consecuencia obligada de la narración cinematográfica-, lo que anula cualquier concepción histórica que de éstas se pudiera obtener por la existencia de errores históricos (intencionados o no), al mismo tiempo que supone un claro caso de intrusismo (como objeción menor peor no por ello carente de importancia); en otras palabras, los filmes quitan autoridad a los historiadores.

Los argumentos esgrimidos por los historiadores suelen hacer referencia a las fuentes consultadas, su valoración y su interpretación, o deberse a posiciones intelectuales 
e ideológicas dispares, mucho más, en cualquiera de los casos, que a determinadas escuelas historiográficas. Las discusiones o debates han terminado por adentrarse en el terreno de los principios metodológicos y la corrección política ${ }^{4}$.

La imagen, la imagen audiovisual, cinematográfica, siempre ha quedado descolgada en lo que a la expresión y divulgación de resultados científicos se refiere. El cauce más reconocido para la publicación científica ha sido siempre el lenguaje escrito $^{5}$. Excepcionales serían los casos de, por ejemplo, Boleslaw Matuszewski, quien propuso ya a finales del siglo XIX la creación de archivos cinematográficos específicos para utilidad y uso de los historiadores. Matuszewski entendía que el cine dejaba así de ser un simple pasatiempo para convertirse en un método agradable para estudiar el pasado, pues permitía "poner las manos, no sobre todo lo que existe sino sobre todo lo que pueda ser tomado, es ya un excelente adelanto para cualquier fuente de información científica o histórica". El cine era y es no sólo una prueba de Historia, sino un fragmento de Historia en sí misma, convirtiéndose además, con el paso de los años, y siempre que se le permita, en un efectivo método de enseñanza ${ }^{6}$.

Desgraciadamente, hoy día, a la hora de hacer públicos y definitivos resultados científicos cualesquiera dentro de la comunidad internacional se utiliza un artículo de revista o un libro. En la transmisión de investigaciones científicas la imagen audiovisual y la palabra oral continúan proscritas; y el motivo no es otro que su consideración poco 'seria', especialmente en lo que a la imagen se refiere pues está muy vinculada a la divulgación ${ }^{7}$, esto es, "a la explicación de cosas importantes a gentes poco ilustradas, poco preparadas para enfrentarse de cara, in media res, con lo racional" (Montero, 2001. Pág.: 42). No hay que olvidar que en muchos casos la práctica totalidad de los espectadores tendrá un primer contacto con un evento histórico determinado -o protagonistas históricos- en el momento del visionado de una película (una consideración subrayada por la tarea divulgadora que ha asumido cierto tipo de cine documental especializado en sucesos bélicos y biográficos, una actividad más centrada en el entretenimiento que en lo científico, aunque el rigor -históricose encuentre siempre presente). Es este un obstáculo que, como se ha encargado de señalar en profesor Montero, dificulta la aceptación del cine, de la imagen audiovisual, como lenguaje adecuado para la comunicación de resultados científicos.

Pero, la influencia que el cine tiene sobre los espectadores es tal que los historiadores se ven obligados a objetar ante su posible aplicación práctica en la historiografía y la enseñanza de la historia en los colegios, institutos y universidades españolas.

Las frecuentes quejas de los historiadores, sobre las inexactitudes e invenciones históricas de las películas, no hacen sino confirmar, sencillamente, la importancia social del cine y su trascendente papel en la conformación de las mentalidades en nuestras sociedades ${ }^{8}$.

Estas palabras quedarían completadas por las expuestas por Santiago de Pablo:

En una sociedad post-alfabetizada como la occidental (en la que la gente sabe leer pero de hecho apenas lee) la ficción audiovisual es la principal fuente de conocimiento histórico para buena parte de la población 9 . 


\section{El cine entra en las aulas}

La carga ideológica, en algunos casos, aunque hay quien defiende que sucede en todos, de las imágenes fílmicas es con toda seguridad el principal motivo del recelo historiográfico. Es, como ya apuntaba unos años atrás Pierre Sorlin, un problema que remite a la problemática de la información en el mundo contemporáneo. Por ello es necesario entender el cine y sus códigos de expresión para poder ofrecer a los alumnos los instrumentos adecuados para poder acercarse al cine, tanto al que ocupe su lugar en la enseñanza como al que rellene su tiempo de ocio.

Ángel Luis Hueso es considerado por muchos el pionero en nuestro país en introducir los estudios que relacionan el cine y la historia. Inspirado por sus trabajos, José María Caparrós Lera, con la ayuda de Rafael de España, introdujo el cine como fuente histórica en nuestra universidad; de forma paulatina se creó, en 1983, el Centro de Investigaciones Film-Història, y en 1989 alumbró una sección de cine dentro del departamento de historia contemporánea de la Universidad de Barcelona gracias al cual se comenzó a impartir la asignatura 'Historia contemporánea y cine'. A través de esta asignatura y de la creación de la revista "Film-Història", editada desde 1991, el profesor Caparrós Lera se ha encargado de divulgar el valor del cine como fuente histórica y herramienta didáctica. Su ejemplo ha servido a otros muchos para impulsar el valor del cine y su aplicación educativa, entre los que cabe citar a Esteve Rimbau, Joaquín Romaguera, José Enrique Monterde, José Luis Sánchez Noriega y Tomás Valero Martínez, creador del sitio web 'CineHistoria.com', un ejemplo de las propuestas voluntariosas a las que al inicio hacíamos referencia y que ofrece, entre numerosos ejemplos de propuestas metodológicas, el apoyo necesario para "la creación de una red virtual de sitios 'web' dedicados a la aplicación didáctica del cine en el sistema educativo español, no sólo en términos ineludibles de su tiempo, sino también, por su condición de medio de comunicación de masas, y por ende, por la influencia socio-cultural que como tal ejerce".

La aplicación del cine dentro de las aulas debe superar el hasta ahora uso ocasional como mera ilustración del contenido vertido por el profesor; es más, para algunos autores la presencia de los filmes ha de ir más allá de la enseñanza historiográfica, debe ser un complemento importante dentro de la educación, pues, como advierte Ramón Breu (2012: 5), "si no estudiamos acompañados del cine y de todo el mundo audiovisual, haremos una mala interpretación de nuestra sociedad".

El cine puede suponer un elemento único de motivación, de conocimiento, de análisis y de debate. Pero, pese al ánimo insuflado desde el mundo del cine español, hoy por hoy las experiencias donde el cine es una herramienta enriquecedora son muy escasas y muy dispersas. Y, lo que es peor, su publicación y comunicación se ve reducida al pequeño ámbito de los docentes e investigadores interesados (muchos de los cuales son los autores de las propuestas y los proyectos en aplicación), por lo que se hace muy difícil llegar a un público más amplio (pese a contar con una amplia participación de sitios web con artículos, reseñas y prácticas, más que de publicaciones en formato libro). 
La mayoría de estas propuestas señalan un elemento fundamental: la formación del profesorado para saber enfrentarse al cine, al filme, y poder así proporcionar las herramientas adecuadas a los discentes. Por no hablar del acondicionamiento de las aulas y los centros (algo que corre peligro debido a los recortes económicos que desde un tiempo a esta parte vienen sufriendo la educación pública patria). También es obligado señalar que el tratamiento de las películas en las aulas se limita, en muchos casos, al contexto histórico, quedando su explotación didáctica un tanto al margen. Existen variedad de modelos de trabajo como el propuesto por Caparrós Lera (2004):

- Ficha técnico-artística.

- Sinopsis argumenta.

- El autor (director, guionista, productor).

- Contexto de la realización del filme (político, sociocultural, económico y cinematográfico).

- Cronología y hechos históricos de la época que el filme evoca.

- Valoración crítica de la película (especialmente desde el punto de vista histórico).

- Bibliografía utilizada.

Valero Martínez, quien incluye las pautas de Caparrós Lera entre sus propuestas metodológicas, señala al mismo tiempo la importancia de un cuestionario que permita al alumno seguir mejor las pautas de trabajo ${ }^{10}$. Pero, "en casi todas las experiencias prima el uso del filme más como pretexto que como texto" (Pla Valls, 2010), en otras palabras, el cine vuelve a ser de nuevo un acompañamiento, aunque no por ello se ha de menospreciar el camino hasta aquí recorrido. El propio Pla Valls señala que su objetivo principal sería el de "reforzar la formación fílmica de nuestros alumnos intentando dar elementos para formar el gusto y el sentido crítico ya que no debemos olvidar que la mayor parte de la visión del mundo que tienen nuestros alumnos la han obtenido de ese 'educador no institucional', en palabras de Sánchez Noriega, que son el cine y otros medios audiovisuales".

\section{Conclusiones}

La importancia del cine en el ámbito historiográfico, y por ende en el docente -el puramente cinematográfico y audiovisual, pero también en el histórico- quedó ya reflejada en su momento a través de las palabras expresadas en 1974 ante la UNESCO por Martin A. Jackson (cofundador de una de las instituciones estadounidenses que mejor ha defendido el papel del cine dentro de la Historia, The Historians Film Committee): 
Es imposible comprender la sociedad contemporánea sin referirse a los filmes que se han venido realizando desde hace 70 años. El cine, y no debemos cansarnos de repetirlo, es una parte integrante del mundo moderno. Aquel que se niegue a reconocerle su lugar y su sentido en la vida de la humanidad privará a la Historia de una de sus dimensiones, y se arriesgará a malinterpretar por completo los sentimientos y los actos de los hombres y mujeres de nuestro tiempo ${ }^{11}$.

Es pues necesario educar la mirada, proporcionar a los alumnos un conocimiento y un aprendizaje en el hecho audiovisual, entre los que se incluye el cine. "Cada año que pasa sin que la cultura audiovisual se enseñe en las escuelas, sin que se reflexione sobre ella, sin que se elabore un análisis crítico del hecho audiovisual y sin que el alumnado pueda expresarse mediante imágenes, se agravan los problemas de interpretación y de comprensión de análisis de la sociedad contemporánea. El analfabetismo mediático es el analfabetismo de nuestros tiempos ${ }^{12}$ ". El cine debe pues ocupar su lugar en las aulas, en las escuelas, en los institutos y en las universidades españolas, el lugar que le corresponde como hecho cultural de primer orden, destacando sus valores educativos y culturales. Es necesaria su incorporación a los currículos oficiales en materia de educación en comunicación, pues en caso contrario se estaría desaprovechando una oportunidad única para comprender mejor nuestra sociedad contemporánea, estudiar y analizar sus problemas y garantizar un futuro para la misma.

Los alumnos digitales de hoy se comunican de forma multimedia, emplean el lenguaje escrito (lo pervierten las más de las veces y es un error no corregirlo por considerarlo una moda pasajera o una posibilidad económica impuesta para el uso de las nuevas tecnologías), la imagen fija y la imagen en movimiento. "El cambio de la cultura impresa a la cultura audiovisual y, posteriormente, multimedia, ha sido liderado por los jóvenes" (Marta Lazo y Gabelas Barroso, 2013: 15). Se hace necesario acercarles las herramientas para fomentar una capacidad crítica y un poder de comprensión y análisis de las mismas, en otras palabras, se hace necesaria una educación en comunicación, en los lenguajes audiovisuales que alcanzan más allá del cine.

Es una tarea que nos queda pendiente, otra más. Pero la enseñanza es un trabajo que no acaba nunca, siempre se puede hacer más, todo puede mejorarse. Depende de nosotros dar los pasos necesarios pues a través de los alumnos construimos el mundo del futuro.

\section{Bibliografía}

AMAR RODRÍGUEZ, Víctor (2003): Comprender y disfrutar el cine. La gran pantalla como recurso educativo. Grupo Comunicar. Huelva.

AMBRÒS, Alba y BREU, Ramón (2007): Cine y educación. El cine en el aula de primaria y secundaria. Grao. Barcelona.

AUMONT, Jacques y MARIE, Michel (1990): Análisis del film. Paidós. Barcelona. 
BREU, Ramón (2012): La historia a través del cine. 10 propuestas didácticas para secundaria y bachillerato. Grao. Barcelona.

CAPARRÓS LERA, José María (2004): 100 Películas sobre historia contemporánea. Alianza. Madrid.

DARIAN-SMITH, Kate y HAMILTON, Paula (ed.) (1994): Memory and history in twentieth-century Australia. Oxford University Press. Melbourne.

DE PABLO, Santiago (2001): Cine e historia: “¿La gran ilusión o la amenaza fantasma?", en Revista Historia Contemporánea, no 22.

FERNÁNDEZ SEBASTIÁN, Javier (1988): Cine e historia en el aula. Akal. Madrid.

FERRO, Marc (1995): Historia contemporánea y cine. Ariel. Barcelona.

FERRO, Marc (1980): Cine e historia. Gustavo Gili. Barcelona.

FERRO, Marc (2008): El cine. Una visión de la historia. Akal. Madrid.

FLORES, Juan Carlos (1982): El cine, otro medio didáctico. Escuela Española. Madrid.

GARCÍA FERNÁNDEZ, Emilio C. (1998): Cine e historia. Las imágenes de la historia reciente. Arco Libros. Madrid.

HEPWORTH, David (1989): "The return of the native", en la Revista Empire.

HUESO, Ángel Luis (1998): El cine y el siglo XX. Ariel. Barcelona.

IBARS FERNÁNDEZ, Ricardo y LÓPEZ SORIANO, Idoya (2006): La historia y el cine, en Revista Clio, $\mathrm{n}^{\circ} 32$.

JACKSON, Martin A. (1983): El historiador y el cine, en ROMAGUERA I RAMIÓ, Joaquim y RIAMBAU, Esteve: La Historia y el Cine. Fontamara. Barcelona.

KRACAUER, Siegfried (1995): De Caligari a Hitler. Una psicológica del cine alemán. Paidós. Barcelona.

MATUSZEWSKI, Boleslaw (1898): "Una nueva fuente de la historia: Creación de un depósito de cinematografía", en Le Figaro.

MONTERDE, José Enrique (1986): Cine, historia y enseñanza. Laia. Barcelona.

MONTERO, Julio (2001): "Fotogramas de papel y libros de celuloide: El cine y los historiadores. Algunas consideraciones", en Revista Historia Contemporánea, $\mathrm{n}^{\circ}$ 22.

MONTERO, Julio y RODRÍGUEZ, Araceli (2005): El cine cambia la historia. Rialp. Madrid.

PAZ, María Antonia y MONTERO, Julio (2008): El cine informativo 1895-1945. Creando la realidad. Ariel. Barcelona.

PLA, Enric y TORRENT, Katia (2003): Taller de cine. Una propuesta didáctica para apoyar el uso del cine en las aulas. Gobierno de Aragón. Huesca.

ROMAGUERA I RAMIÓ, Joaquim y RIAMBAU, Esteve (1983): La Historia y el Cine. Fontamara. Barcelona.

ROSENSTONE, Robert A. (1997): El pasado en imágenes. El desafio del cine a nuestra idea de la historia. Ariel. Barcelona.

SORLIN, Pierre (2005): "El cine, reto para el historiador", en Revista Istor de Historia Internacional, $\mathrm{n}^{\mathrm{o}} 20$. 


\subsection{Recursos electrónicos}

MARTA LAZO, Carmen y GABELAS BARROSO, José Antonio (2013): “Hábitos de consumo televisivo de ficción entre los universitarios que estudian comunicación", en Revista de Comunicación de la SEECI, n 31, año XVII, julio. Disponible en http://www.seeci.net/revista/index.php/seeci [14 de mayo de 2013]

PLA VALLS, Enric (2010): Historia en el cine, cine en la historia. Disponible en www.cinehistoria.com [14 de mayo de 2013]

www.auladecine.com

wWw.cinehistoria.com

www.educahistoria.com

www.pcb.ub.es/filmhistoria

\section{Notas}

1 Tampoco es necesario caer en la educación-espectáculo, convirtiendo al profesor en un animador profesional que ha de estar constantemente motivando a los alumnos para que éstos puedan interesarse por los conocimientos de las materias. Llegar a ese extremo es igual de peligroso que el opuesto, seguramente más real de lo que muchos quisieran, aquel en el que el profesor transmite unos conocimientos (en muchos casos recurriendo a aquellos autores considerados expertos) para unos pocos que están interesados, el resto se verá arrastrado por la marea, cada vez mayor debido a la masificación de las aulas. Esta situación también dificulta, y mucho, la labor docente, haciendo necesarias herramientas que conecten a unos y otros, pese al gran número de alumnos, y eso es lo que ofrecen las tecnologías de la información y la comunicación.

2 La profesora Victoria Tur Viñes (Universidad de Alicante) comentó durante su participación en el congreso CUICIID 2013 la gran cantidad de premios que acompañan a los productos de consumo infantiles especialmente, desde cajas de cereales hasta postres, pasando por las tradicionales chucherías, y cómo, esta actividad influye sobre el comportamiento, adaptando a los niños y a los jóvenes a una cultura consumista donde nada merece la pena si no conlleva una recompensa material.

3 La juventud, cada vez menor, de la historia del cine como disciplina autónoma, así como la cotidianeidad del cine, han jugado siempre en su contra. De los biógrafos primitivos, los cronistas antiguos, eruditos clásicos hasta los académicos modernos señalados por Luis Alonso García como algunas de las etapas por las que ha pasado la historiografía cinematográfica (El extraño caso de la historia universal del cine, Episteme, Valencia, 2000), la mayor parte de los autores especializados en historia del cine carecían de formación en historiografía, lo que provocaba errores incomprensibles al no acudir a los archivos o recoger de forma acrítica los dicho por historiadores anteriores sin confirmación de fuentes o un contraste actualizado. Sirva como ejemplo el citado por Jon Letamendi Garate y Jean-Claude Seguin Vergara en La cuna fantasma del cine español (Cims 97, 1998) sobre la discusión acerca de la primera película realizada por un español y que derivo en la celebración de un centenario oficial de un filme mal fechado pero que nadie se molestó en comprobar.

4 Pierre Sorlin destaca cuatro reproches habitualmente atribuidos a los cineastas: propones interpretaciones erróneas, dan demasiado lugar al relato, privilegian los casos individuales en relación con las tendencias generales y les dan demasiadas ventajas a los actores.

5 La exposición exacta de los resultados científicos obliga a eliminar cualquier atisbo de polisemia. Pese a las posibilidades que ofrece la comunicación oral o la audiovisual, sus inconvenientes siguen pesando mucho más, piénsese en las modulaciones y diferentes tonos de voz y los múltiples signi- 
ficados que de ellos se pueden extraer, o la edición audiovisual que obliga a la utilización de elipsis por ejemplo. La riqueza de significados y la estética en la expresión están muy reñidas con el rigor científico.

6 Aunque las expectativas que Matuszewski tenía sobre la aplicación docente del cinematógrafo eran excesivas, entendía éste como algo incontestable y absolutamente verdadero sin posibilidad de modificación o alteración voluntaria, su necesidad de aplicación en la enseñanza no era para nada descabellada, como corroboran las palabras citadas al inicio de Edison y Griffith.

7 "A pesar de que nos adentramos en el siglo XXI con toda la cultura (o incultura) audiovisual inoculada dentro de nuestro intelecto, todavía vivimos en la persistente dinámica que entroniza las metodologías vinculadas a la documentación escrita como 'las de verdad”' (Breu, 2012: 6).

8 MONTERO, Julio, op. cit.. Pág.: 53.

9 DE PABLO, Santiago (2001): Cine e historia: ¿La gran ilusión o la amenaza fantasma?, en Revista Historia Contemporánea, $\mathrm{n}^{\circ}$ 22, pág.: 23.

10 El profesor Javier Vicente Martín y Katia Torrent, conductora del proyecto Cine e historia, insisten en el valor de la documentación previa que se da a los estudiantes y en la importancia de sacar partido a lo visto con actividades bien programadas.

11 JACKSON, Martin A. (1983): El historiador y el cine, en ROMAGUERA I RAMIÓ, Joaquim y RIAMBAU, Esteve: La Historia y el Cine. Fontamara. Barcelona. Pág.: 21.

12 Ambròs y Breu (2007: 20) insisten en este punto: "la ignorancia y la falta de cultura audiovisual que padecemos no han venido solas, vienen avaladas por el modelo mayoritario de televisión. Es decir, el modelo dominante de televisión que nos convence de que la única manera de construir imágenes y contenidos audiovisuales es la suya: una caja imponente de formatos televisivos que insiste en la miseria cultural, en la humillación intelectual y personal, en unas formas de diversión rutinarias y empobrecedoras, en la trivialización de los valores democráticos, en la promoción de contravalores, en la exaltación de la pasividad crítica y en la alienación más deprimente de la ciudadanía".

\section{El autor}

José Rodríguez Terceño es licenciado en Comunicación Audiovisual por la Universidad Complutense de Madrid y doctorando en la rama de cine de la misma institución. Miembro del Grupo de Investigación Validado Complutense Concilium, ha participado en diversas publicaciones colectivas centradas en la séptima arte, periodismo y las relaciones públicas. 